\title{
RESPONSE OF DAMAGED AND UNDAMAGED TAILORED EXTENSION-SHEAR-COUPLED COMPOSITE PANELS
}

\author{
Donald J. Baker* \\ Vehicle Technology Directorate - ARL \\ NASA Langley Research Center \\ Hampton, VA 23681
}

\begin{abstract}
$\underline{\text { Abstract }}$
The results of an analytical and experimental investigation of the response of composite I-stiffener panels with extension-shear coupling are presented. This tailored concept, when used in the panel cover skins of a tiltrotor aircraft wing has the potential for increasing the aeroelastic stability margins and improving the aircraft productivity. The extensionshear coupling is achieved by using unbalanced $\pm 45^{\circ}$ plies in the skin. Experimental and STAGS analysis results are compared for eight I-stiffener panel specimens. The results indicate that the tailored concept would be feasible to use in the wing skin of a tiltrotor aircraft. Evaluation of specimens impacted at an energy level of 500 in.-lbs indicate a minimal loss in stiffness and less than 30 percent loss in strength. Evaluation of specimens with severed center stiffener and adjacent skin indicated a strength loss in excess of 60 percent.
\end{abstract}

\section{Introduction}

One of the principal design challenges for the high-speed tiltrotor transport aircraft is achieving acceptable proprotor aeroelastic stability margins, which can restrict the operating airspeed of the tiltrotor aircraft in the high-speed airplane mode. The primary mechanism responsible for the proprotor stability problems is discussed by Popelka, et al ${ }^{1}$ and will be briefly reviewed here. Historically, the most critical modes affecting the proprotor stability are the symmetric wing beamwise bending mode (SWB) and the symmetric wing chordwise bending mode (SWC). For these modes, the rotor can create destabilizing inplane hub forces, which can overcome the structural and aerodynamic damping of the wing at high speed and can cause instability. The in-plane shear forces are generated by the rotor in response to the pylon pertur-

* Aerospace Engineer, Mechanics and Durability Branch.

This material is a work of the U. S. Government and is not subject to copyright protection in the United States. bation pitch angle and pitch rate. The wing SWB mode, SWC mode and symmetric wing torsion (SWT) mode dictate the pylon pitch rate and pitch angle. Proprotor stability can be influenced by changing the frequency placement of the wing modes and by modifying the mode shapes to alter the pylon dynamic response and reduce the destabilizing in-plane hub forces.

Minimizing the pylon pitch motion in the fundamental wing modes can affect the proprotor stability. Minimizing the pylon pitch component reduces the rotor destabilizing forces and increases the stability boundary as shown in Figure 1. In a typical tiltrotor wing design, the rotor pylon pitches up as the wing bends upward in the SWB mode. For a conventional composite wing design with structurally balanced skin laminates, the wing provides no structural

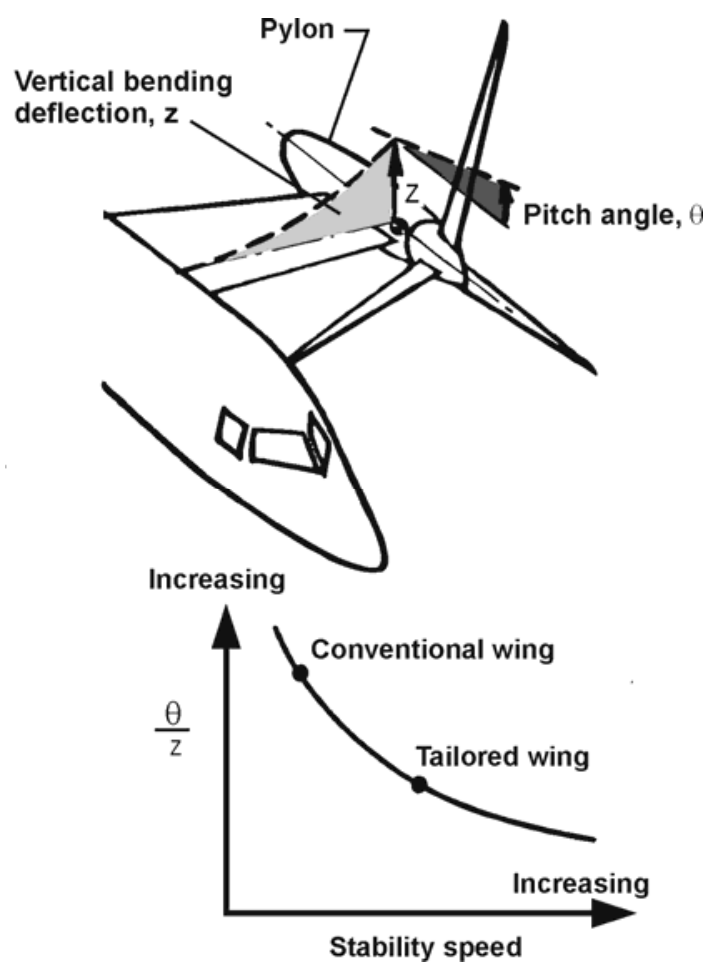

Figure 1. - Influence of structural tailoring on wing aeroelastic stability. 
pitch/bending coupling to resist the nose up pitch due to pylon mass offsets. Unbalanced composite skins, on the other hand, can create nose down structural twist as the wing bends upward to offset the pitch up tendency from the pylon mass offsets. The net effect is reduced pitch/bending coupling and improved stability. The preceding discussion applies to the SWB mode only.

The effects of structural tailoring can be simply shown by considering the cantilever boxbeam shown in Figure 2a. The direction of the $-45^{\circ}$ plies are shown on the figure. The forward and aft spar web is a balanced $\pm 45^{\circ}$ laminate. The upward bending from the pylon produces a compression load in the upper skin and a tension load in the lower skin as shown in Figure 2a and 2b. The compression load in the upper skin produces a deflection in the forward direction. The tension load in the lower skin produces a deflection in aft direction. These deflections in the skins combine to produce a couple that results in a nose down pitch as shown in figure $2 \mathrm{c}$.

The feasibility of a composite tailored wing for a high-speed civil tiltrotor transport aircraft has been addressed by Popelka, et $a l^{2}$, using current analytical methods to design a tailored composite wing for a tiltrotor transport aircraft. Parametric studies show that
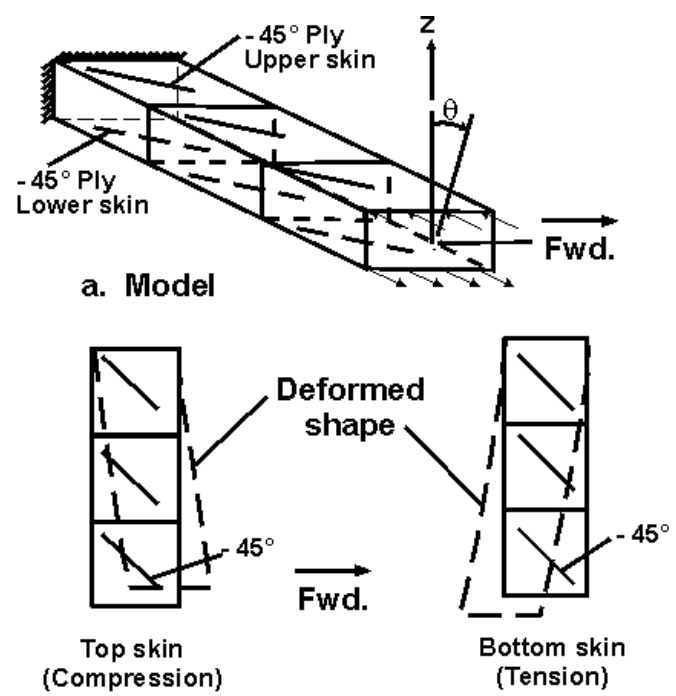

b. Top View

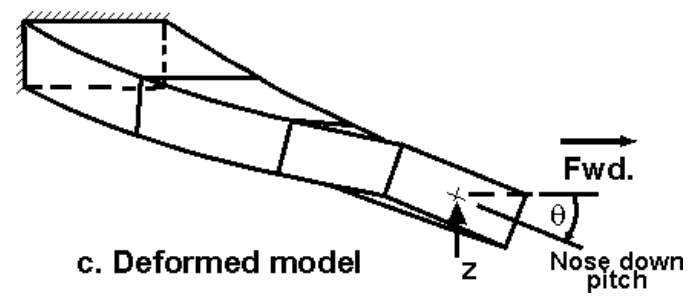

Figure 2. - Simple boxbeam model. the overall stability gains from composite tailoring can be limited because of conflicting structural design requirements imposed by the two critical modes of instability, SWB and SWC, and the necessity to balance the stability boundaries for both modes. The SWC mode stability can be improved by increasing the chordwise bending stiffness of the wing. The final tailored wing configuration was a three-stringer configuration with a $70 / 30$ blend ratio of $-45^{\circ} /+45^{\circ}$ plies for the skin laminate along with stringer cap and spar cap tailoring to improve the SWC mode.

A 1/5-scale wing model was designed to have the same elastic characteristics as the full-scale tailored wing and was tested in a semi-span aeroelastic model to demonstrate that composites techniques can be used to improve proprotor stability. ${ }^{3}$ A direct comparison between the baseline and tailored wing stability boundaries indicates an increase over baseline of approximately 30 knots in the scaled model or 58 knots in the full-scale design. For a full-scale design, the 58 knot increase in the stability boundary represents a significant improvement.

The objective of the present study is to assess the detailed structural response of tailored panels with and without damage. Specifically, this research addresses: a) development of a test method for testing coupled specimens and b) demonstration of the coupled response of the full-scale wing panel subcomponents with and without impact and discrete source damage. The analytical and experimental results of the study are presented and compared to illustrate the predictive capability for stiffened, anisotropic panels.

\section{Test Specimens}

The panels to be evaluated were designed by Bell Helicopter, Textron, using the results of the study by Popelka. ${ }^{2}$ A cross-section of the stiffener and skin is shown in Figure 3b. The skin is 21 plies increasing to 47 plies under the I-stiffener using Grade 190 IM63501-6 carbon-epoxy tape material. The skin orientation is $\left[45 / 90 /-45_{3} / 45 /-45_{3} / 45 / \overline{0}\right]_{s}$ where $67 \%$ of the $45^{\circ}$ plies are oriented at the negative angle. The ply orientation for the reinforced area under the stiffener is $\left[45 / 90 /-45_{3} / 45 / a / 0_{3} / a /-45_{2} / a / 0_{4} / a /-45 / 45 / 0 / 45 /-\right.$ $\left.45 / \mathrm{a} / 0_{4} / \mathrm{a} /-45_{2} / \mathrm{a} / 0_{3} / \mathrm{a} / 45 /-45_{3} / 90 / 45 / \mathrm{a} / 45^{\mathrm{f}} /-45^{\mathrm{f}} / \mathrm{a}\right]$. Where "a" identifies a 0.008-inch-thick layer of FM300 adhesive. The I- stiffener is made from back-to-back C-channels which have the following layup: [$\left.45 / 90_{2} / 45 / 0_{4} /-45 / 0_{4} / 45 / 0_{4} / 45 / 0_{2}\right]$. The cap of the I-stif- 
fener has a layup of $\left[0_{2} /-45 / 0_{4} /-45 / 0_{4} / 45 / 0_{4} /-45 / 90_{2} / 45\right]$. The material for the stiffener and cap is Grade 95 IM63501-6 carbon-epoxy material. The stringer spacing is 7.5 inches, which gives an overall panel width of approximately 19 inches.

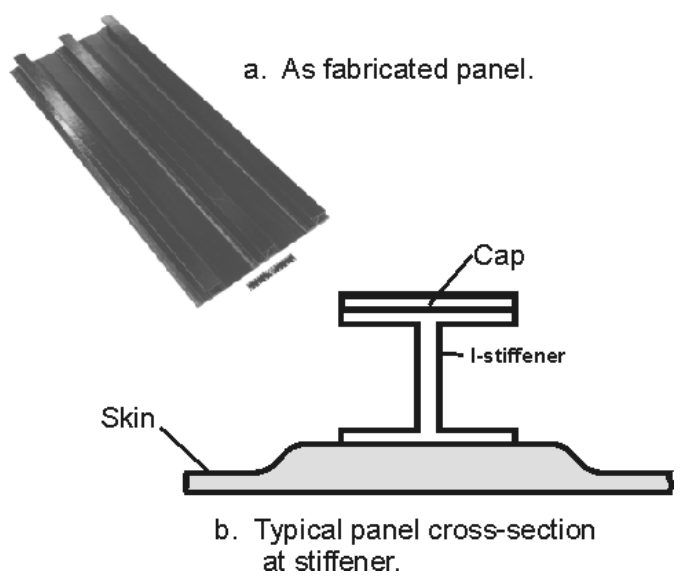

Figure 3. Specimen configuration.

Four 4-foot-long panels, as shown in Figure 3a, were manufactured at two different times. These panels were cut into 23-inch-long test specimens, potted and ground flat and parallel. These test specimens will be identified as TP-1 through TP-8 in the remainder of the paper. Specimens TP-1, TP-2, and TP-6 were tested in the as-fabricated (undamaged) condition. A slot was cut through the center stringer and adjacent skin on specimens TP-4, TP-5, and TP-7. Specimens TP-3 and TP-8 were subjected to low-speed impact at the thickness transition at the center stringer. Previous testing ${ }^{4}$ on non-tailored panels with the same design indicated that the thickness transition area is a critical point and 500 in.-lbs of impact energy produced barely visible impact damage.

\section{$\underline{\text { Test Procedure }}$}

All specimen tests were performed at room temperature, with no environmental conditioning. The specimens were placed between the platens of a 600 kip or 1200 kip hydraulic test machine and loaded in compression. The load rate varied depending on the specimen condition. For example, the undamaged specimens were loaded at $20 \mathrm{kips} / \mathrm{min}$. while the specimens with the central slot were loaded at 5 kips/min.

Impact testing was performed using a dropped weight impactor, utilizing a 25 pound weight with a 1.0-inch diameter spherical impactor. The energy level was 500 in.-lbs and was intended to produce barely visible impact damage.

All specimens were instrumentated with strain gages with the number of gages varying with specimen condition. Specimen strain gage instrumentation patterns are shown later in the paper. Out-of-plane displacement were measured using linear variable displacement transducers (LVDT) at selected locations. The load, strain, out-of-plane and head displacements were recorded with a computer-controlled data acquisition system for each test. In addition to the strain gages and displacement transducers used during the test, a three-dimensional image correlation technique $^{5}$ was also used. This full-field-displacement measurement technique utilizes a camera-based stereovision system. This is a non-intrusive system since the only part of the measurement system that comes into contact with the test specimen is a spackle pattern that is applied to the surface of the test specimen to establish the specimen displacement tracking points. The spackle pattern that is applied to the surface of the test specimen can be a thin contact film with a black spackle pattern printed on the film or black paint dots on a white background. Images of the changing pattern on the test specimen surface are recorded at user specified time intervals to monitor the displacement field.

Testing a tailored panel with extension-shear coupling presents some unique challenges. It is necessary to maintain a uniform applied displacement along the end of the panel as the panel changes shape due to the extension-shear coupling, from a rectangle to a parallelogram as shown in Figure 4. Maintaining a uniform displacement and allowing the end of the test

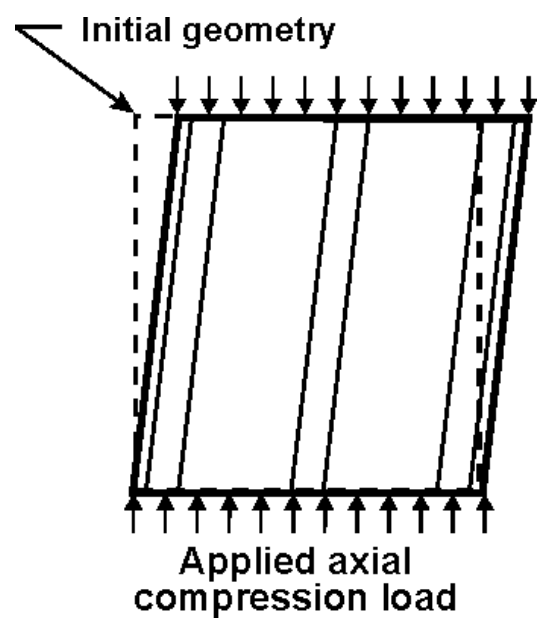

Figure 4. Effect of extension-shear coupling on panel response. 
specimen to move in-plane required a test fixture as shown in Figure 5. The fixture shown in Figure 5 is attached to the end of the test specimen. The rollers shown allow the test specimen to move in-plane while the axial displacement is applied to the top plate with a test machine.

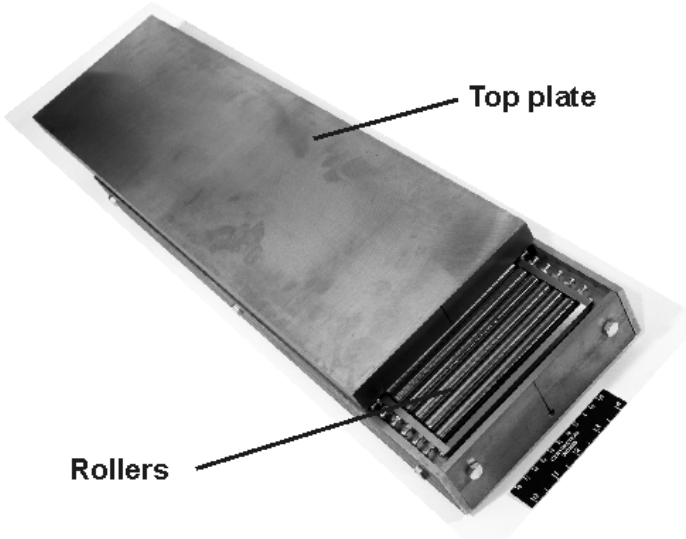

Figure 5. Test fixture for panels with coupled in-plane response.

\section{$\underline{\text { Results and Discussion }}$}

Since there are three types of specimens; a) undamaged: b) with cut center stringer and adjacent skin: and c) impact damaged, results for each type will be presented individually. Each section will include a brief specimen description, comparison of analysis and test results, and failure mode description. Finite element analysis of the panels was conducted using STAGS nonlinear analysis code ${ }^{6}$ to determine test specimen response. STAGS (STructural Analysis of General Shells) is a general-purpose finite element analysis code for the analysis of shell structures of arbitrary shape and complexity.

\section{Undamaged Specimens}

The STAGS finite element model of the undamaged specimen is shown in Figure 6. This model contained 12,420 of STAGS 4-node quad elements (element 410 in STAGS library) and 12,649 nodes. Analysis results for an undamaged specimen are presented in Figures 7 and 8 for an applied load, P, in the y-direction. The fringe pattern shown in Figure 7 is for the w-displacement field (out-of-plane) in the test specimen. The analysis predicted localized out-ofplane displacements at each end in the skin as shown by the tear drop shaped contours. Due to skin displacements, the center stiffener is predicted to deflect out-of-plane but there is no indication of the edge stiffeners deflecting out-of-plane. The fringe

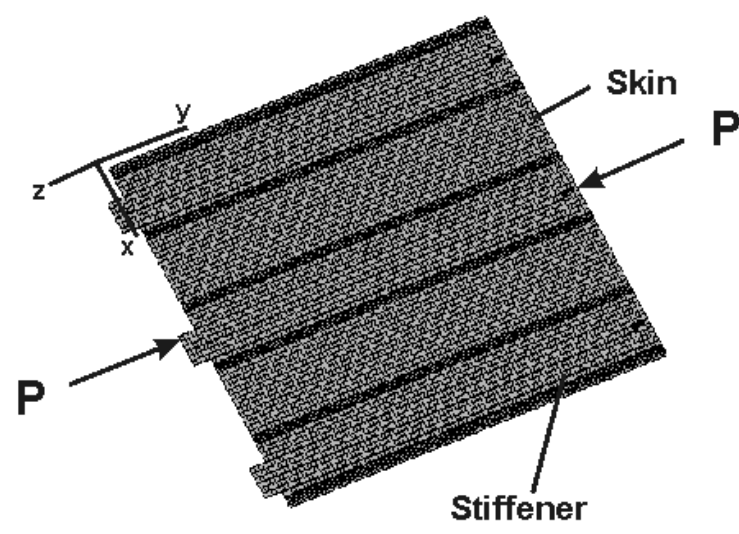

Figure 6. Finite element model of undamaged test specimen.

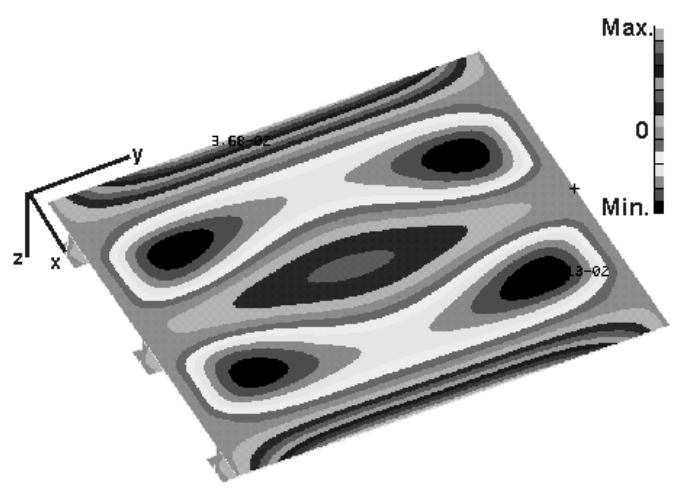

Figure 7. Typical analytical out-of-plane displacements contours.

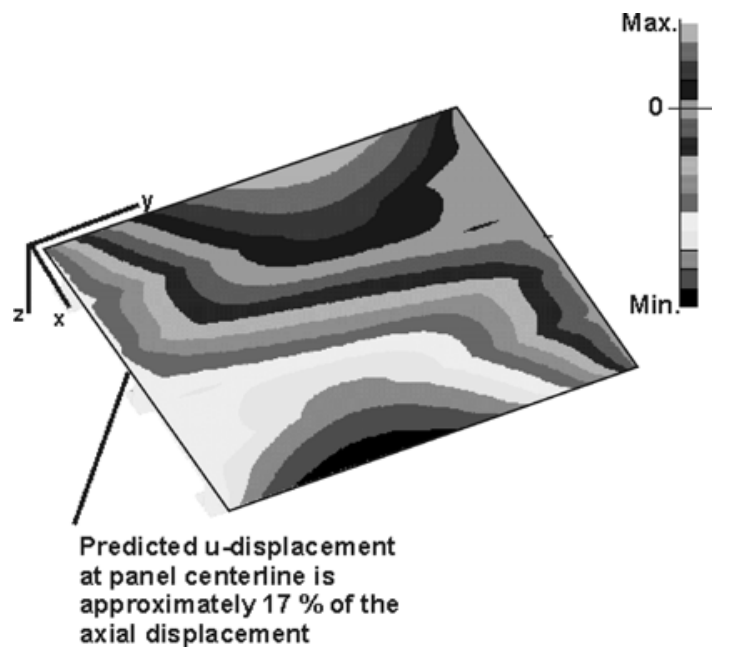

Figure 8. Typical analytical in-plane displacement contours.

patterns shown in Figure 8 are for the u-displacement field (normal to the stiffener direction) in the test specimen. The effect of the extension-shear coupling is 
indicated by the skewed pattern of these fringes. The predicted u-displacement in the panel is approximately 17 percent of the $\mathrm{v}$-displacement. Only the $\mathrm{u}$ displacement at the panel centerline is considered when computing the in-plane displacement to eliminate the Poisson effect on the specimen edges.

The linear buckling analysis of the undamaged specimen predicted the first mode buckling at 31.12 kips/in.

Three undamaged specimens, TP-1, TP-2, and TP-6 have been tested. A photograph of TP-1 is shown in Figure 9, along with the strain gages. Specimens TP1 and TP-2 had a total of 36 strain gages each, located along the specimen mid-length and quarter-point length as shown in Figure 9. The other undamaged specimen, TP-6, was instrumented with 18 strain gages along the quarter point length.

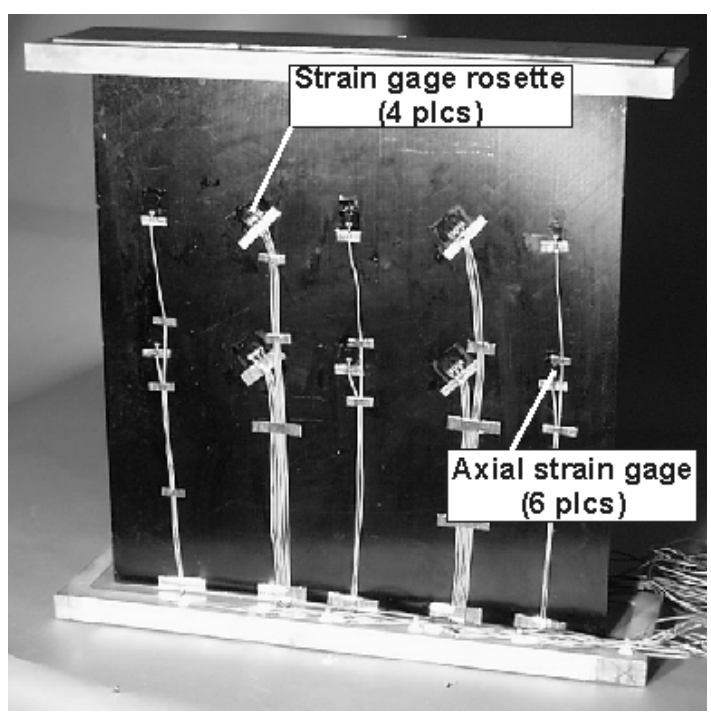

Figure 9. Test specimen, TP-1.

The undamaged specimens were loaded in compression at the rate of $20 \mathrm{kips} / \mathrm{min}$. until failure. The failure loads are shown in Table 1 for each specimen. The average failure load was $20.43 \mathrm{kips} / \mathrm{in}$. One specimen of a similar design with a balanced $\pm 45^{\circ}$ skin stacking sequence, has been tested with a failure load of $22.7 \mathrm{kips} / \mathrm{in} .{ }^{4}$ The tailoring reduces the failure strength by approximately 10 percent. A plot of the specimen axial end shortening (solid lines) and transverse in-plane displacement (dashed lines) as a function of load are shown in Figure 10. The slope of the axial displacement curve is considered a measure of the specimen stiffness. The stiffness of each specimen is shown in column 3 of Table 1 . The average
Table 1. Undamaged specimen loads and stiffnesses

\begin{tabular}{llll}
\hline \hline $\begin{array}{l}\text { Specimen } \\
\text { Number }\end{array}$ & $\begin{array}{l}\text { Failure } \\
\text { load, } \\
\text { kips/in. }\end{array}$ & $\begin{array}{l}\text { Stiffness, } \\
\text { kips/in./in. }\end{array}$ & $\mathrm{P}^{\mathrm{a}}$ \\
\hline TP-1 & 21.64 & 144.42 & 0.25 \\
TP-2 & 20.59 & 146.21 & 0.25 \\
TP-6 & 19.07 & 147.89 & 0.17 \\
\hline \hline
\end{tabular}

${ }^{\mathrm{a}}$ In-plane displacement is $\mathrm{P}$ times the axial displacement.

specimen stiffness of 146.17 kips/in./in. is approximately 5 percent lower than the computed stiffness of 153.89 kips/in./in. The transverse in-plane (dashed line) plot for each specimen indicates the amount of in-plane displacement that resulted from the coupling. The amount of in-plane displacement as a percentage of the axial displacement, for each specimen, is shown in column 4 of Table 1 . The computed in-plane displacement is 0.17 times the axial displacement. The difference between analysis and test results for specimens TP-1 and TP-2 could be because they were produced in different batches compared to specimen TP-6.

Strain gage results from gages located at the quarter point of specimen TP-1 length are shown in Figure 11. The back-to-back gages (Figure 11a) indicate bending in the center stiffener and no bending in the outer stiffeners. As shown in Figure 11a the stiffeners do not carry a uniform strain across the

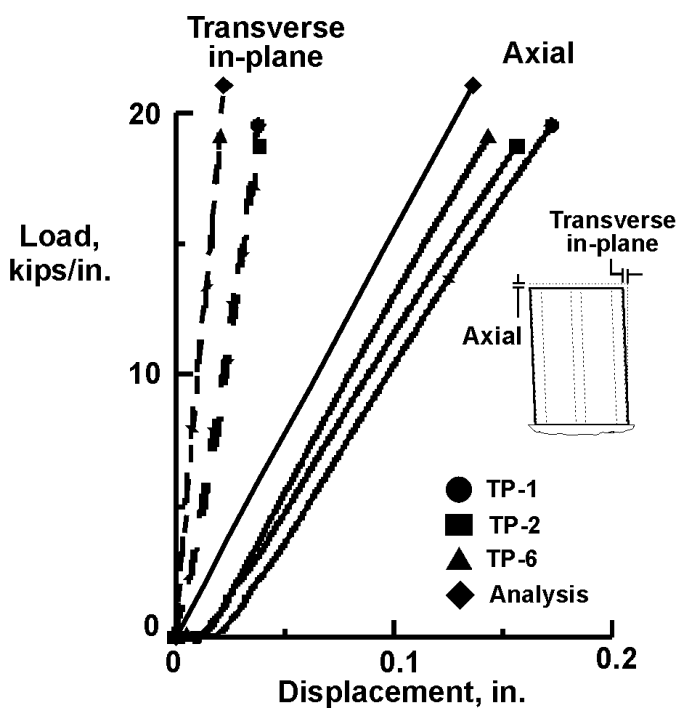

Figure 10. Axial and in-plane displacement as a function of applied load. 
specimen width with the strains at failure varying from $0.002 \mathrm{in}$./in. in the center stiffener to $0.006 \mathrm{in}$./in. in the stiffener denoted by the triangle symbols. Results from the skin bays indicate some bending and a tension strain of approximately 0.002 in./in. These strain gages are located in areas where the analysis predicted an out-ofplane deflection. The shear strains in the skin denoted by the triangle symbol indicate less than 0.0005 strain, while the other skin bay indicated approximately 0.002 strain. There are very small shear strain gradients through the thickness of the skin panel. The axial strain gages at the center of specimen TP-1 were all near 0.006 in./in. at failure and indicated a slight nonlinearity as a function of load. The strain gage results indicated some bending in the center I-stiffener at the specimen centerline as predicted by analysis. The shear strain in the skin bays at specimen centerline had up to 0.002 shear strain gradient through the skin thickness. These observations suggest that the strain state in the panels is very complex.

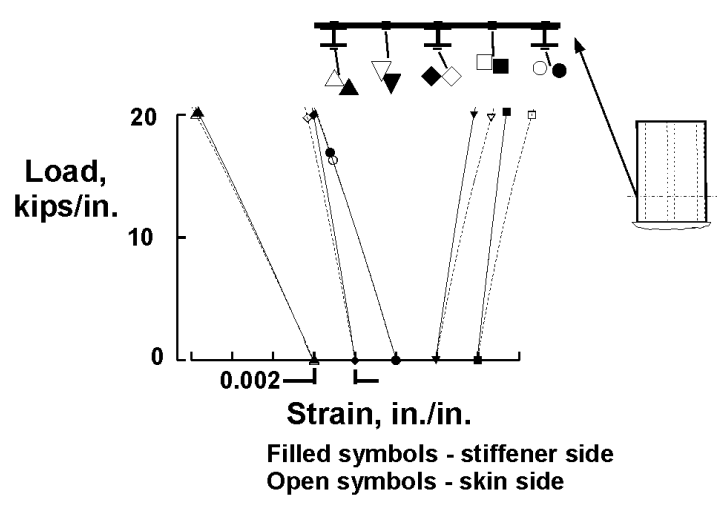

a) Axial strain

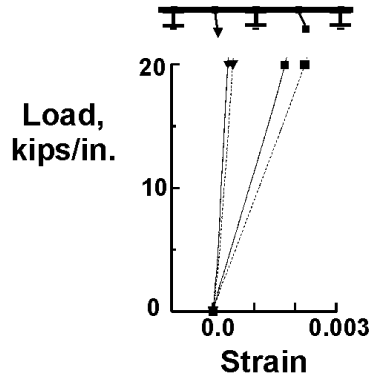

b) Shear strain

Figure 11. Load-strain results for specimen TP-1 along a line at the specimen quarter length.

In addition to the strain gages and displacement transducers used during the testing, a three-dimensional image correlation system, described previously, was also used. Some of the results that have been obtained from the image correlation system on specimen TP-1 are illustrated in Figure 12. As shown in Figure 12, the image area covered approximately top one-half of the specimen surface area. The first image taken in any test determines the profile (or flatness) of the specimen at no load. Specimen TP-1 profile is shown in Figure 12a and indicates the specimen surface profile varies from a theoretical plane by +0.010 -inches to -0.005 -inches. Each contour line represents a constant distance from a theoretical plane. The initial imperfections are tracked to access the reproducibility of these tailored panels. U-displacement contours are presented in Figure 12b. These contours indicate that the in-plane displacement is approximately 16 percent of the axial displacement. The effect of the specimen Poisson's ratio, which is nearly unity for the skin laminate, can be observed along the edges of the specimen. The v-displacement contours shown in Figure 12c indicate a nearly uniform axial loading of the panel. The w-displacement contours are shown in Figure 12d. The skin between the I-stiffeners and located between the quarter point and the specimen end deflect up to 0.06-inches out-ofplane. This out-of-plane displacement magnitude compares well with the analysis results. The skin deflections are maximum in the bay on the left side of the figure. The analysis (see Figure 7) also predicts the skin deflection on one side of the center stiffener will have a greater magnitude.

The profile of specimen TP-6 is shown in Figure 13. The image area of this specimen is larger than the area shown in Figure 12 and extends approximately 3-inches past the centerline. The out-offlatness of this specimen varies from -0.005 -inches to +0.06 -inches from a theoretical plane.

The strain on the surface viewed with the image correlation system can be computed from the displacement measurements. The $\varepsilon_{\mathrm{yy}}$ strain computed from the displacements on specimen TP-6 skin surface is shown in Figure 14. The strain on the skin surface shown in figure 14 varies from +0.001 in./in. (near top edge) to $-0.007 \mathrm{in} . / \mathrm{in}$. for a load of $18.87 \mathrm{kips} / \mathrm{in}$. with the maximum compressive strain located approximately 2-inches above the specimen centerline. The predicted surface strain for a load of $18.95 \mathrm{lbs} / \mathrm{in}$. is shown in Figure 15. The predicted strain in the central area of the specimen is $0.0061 \mathrm{in} . / \mathrm{in}$. and compares well with the strain determined from the image correlation system. The analysis results indicate strain concentration at each end in the skin. This effect is also indicated in Figure 14, along the top edge. 


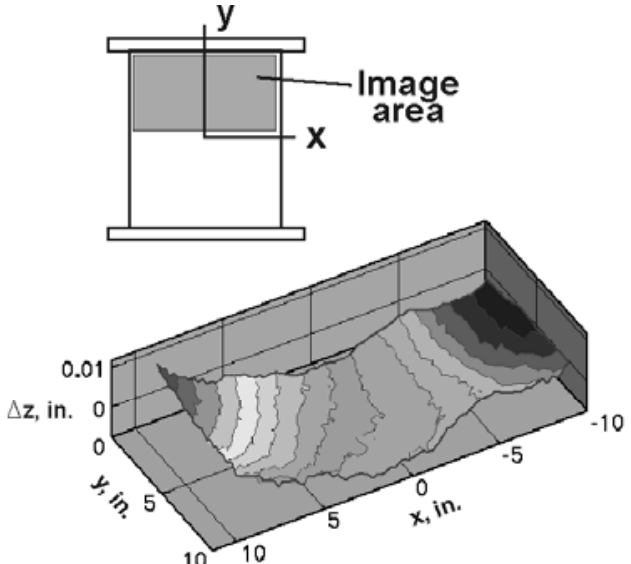

a) Panel out-of-plane flatness contours

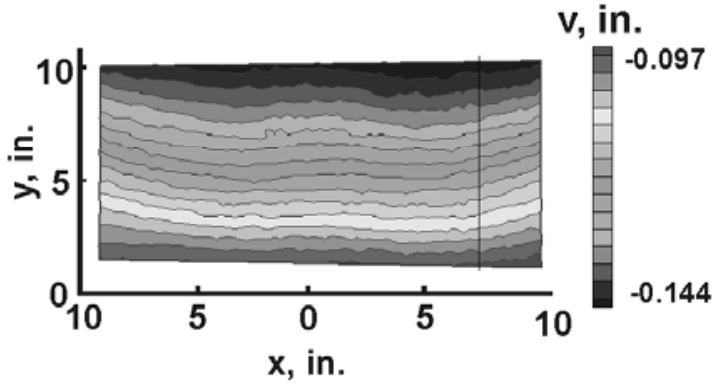

c) v - displacement contours

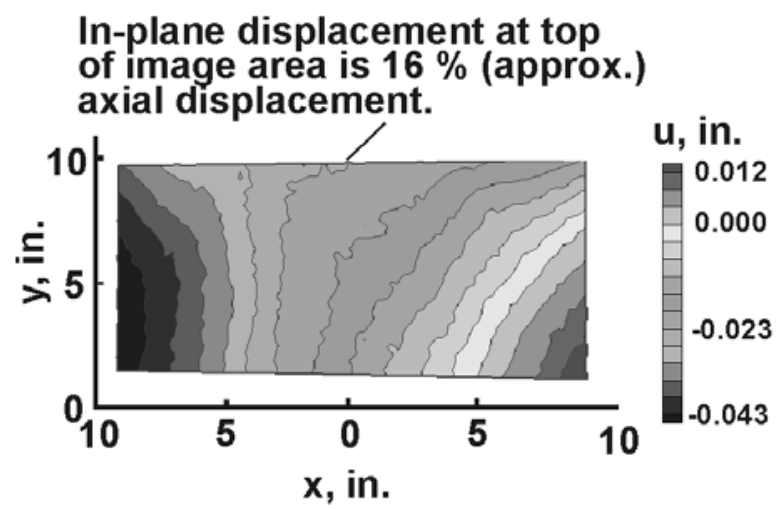

b) $\mathrm{u}$ - displacement contours

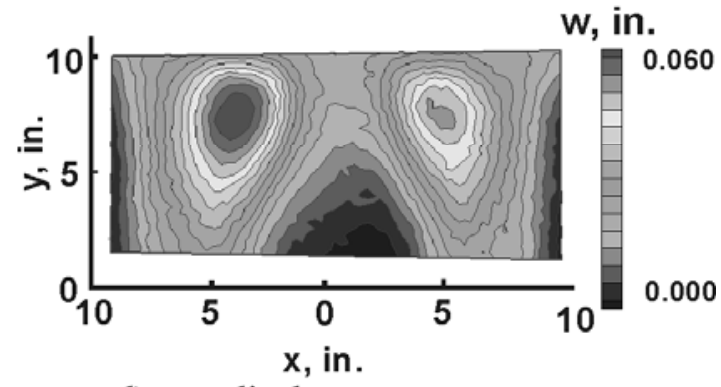

d) $\mathrm{w}$ - displacement contours

Panel TP1 - Image taken at load = 410 kips.

Figure 12 Results obtained from the image correlation analysis on specimen TP-1.

$\Delta z$, in.

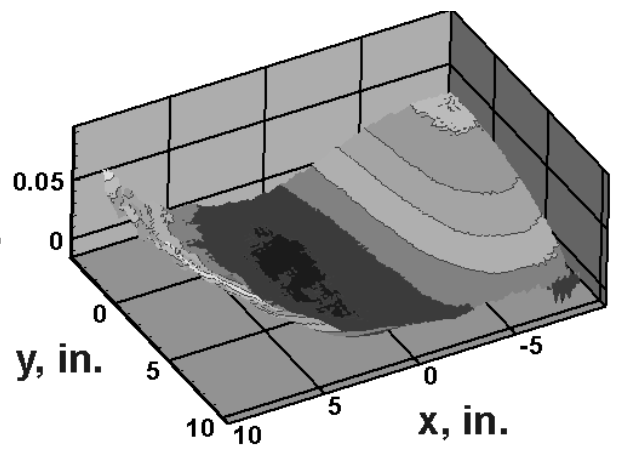

Figure 13. Profile of specimen TP-6.

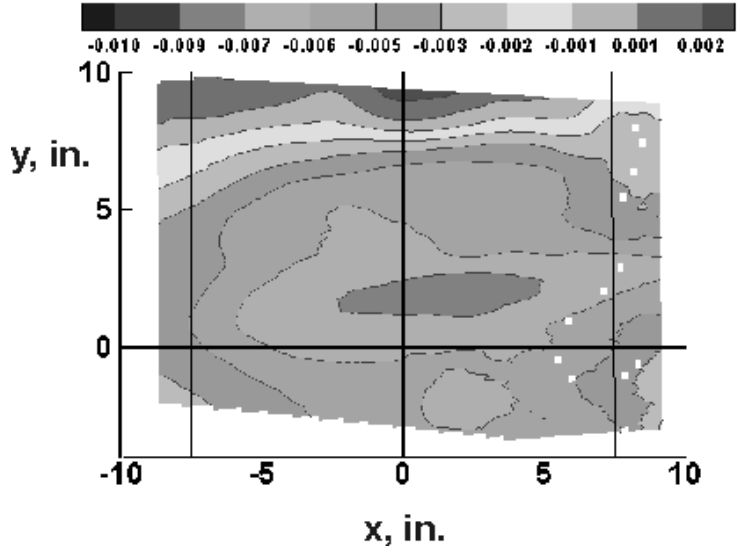

Figure 14. Skin surface strains $\left(\varepsilon_{\mathrm{yy}}\right)$ for specimen TP-6 at 18.87 kips/in. load. 


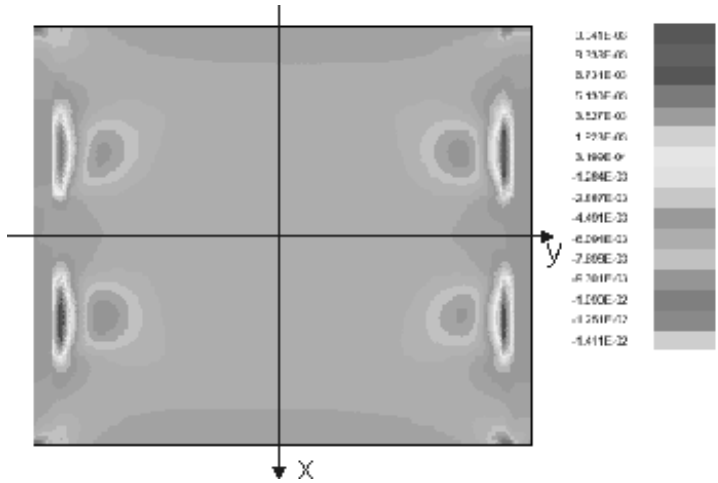

Figure 15. Predicted strain on TP-6 skin surface.

Photographs of failed specimen TP-6 are shown in Figure 16. The stiffeners failed along the bondline with the skin. The failure has both adhesive and cohesive characteristics. The skin also failed in one corner as shown in Figure 16. Specimens TP-1 and TP2 also failed by stringer separation similar to specimen TP-6.

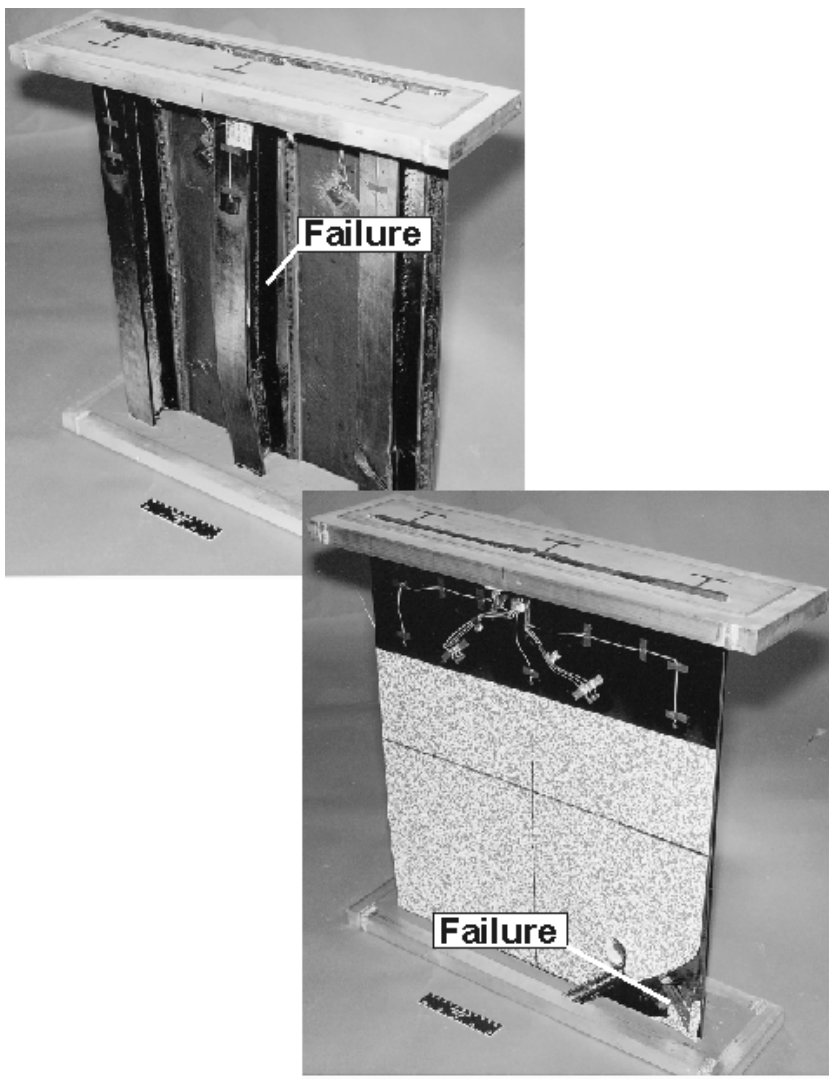

Figure 16. Failed Specimen TP-6.

\section{Damaged specimens}

Horizontal cut. The specimens, TP-4 and TP-7, were damaged by cutting the center stringer and adjacent skin as shown in Figure 17. The slot extends between the center of each skin panel and is 0.38-inch-wide at the center of the specimen tapering to 0.18 -inch-wide at the ends with a tip radius of 0.09 -inch.

The STAGS finite element model of the damaged specimen with a horizontal slot is shown in Figure 18. This model contained 12,771 quad elements and 12,494 nodes. Predicted displacement results are shown in Figure 19 for a specimen with a horizontal slot. These contours (Figure 19a) do not have the skewed pattern shown in Figure 7 for the undamaged specimen. The severing of the center stiffener and adjacent skin minimizes the extension-shear coupling in the specimen. The contours shown in Figure 19b indicate the load redistribution around the central slot.

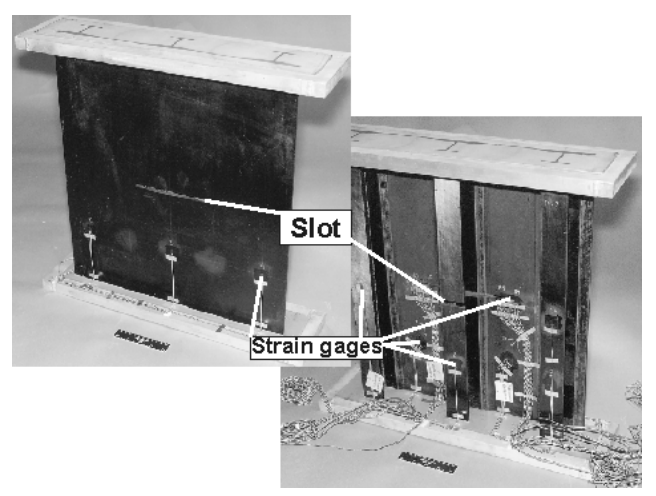

Figure 17. Specimen with horizontal slot.

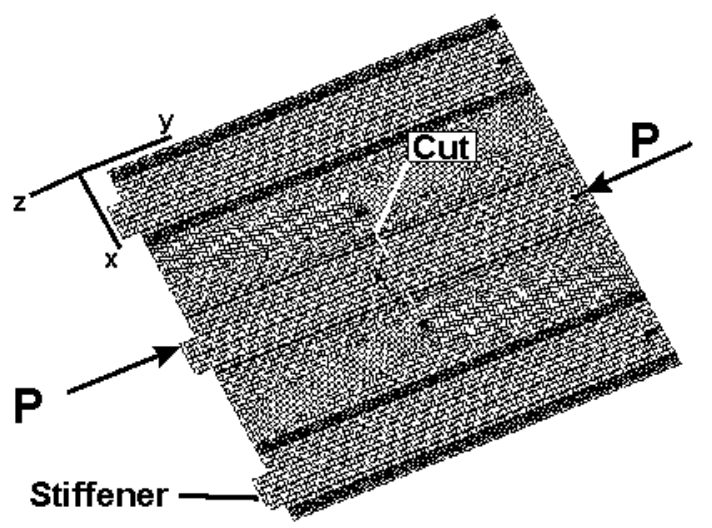

Figure 18. Finite element model of specimen with horizontal slot. 
The large triangular area to the right of the slot in Figure 19b indicates no axial displacement. Figure 19c indicates an out-of-plane bulge caused due to severing the central stiffener.
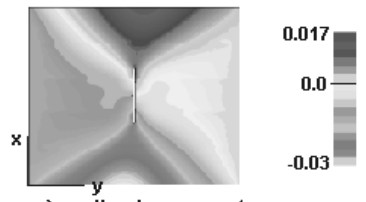

a) u-displacement

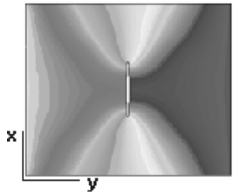

b) v-displacement
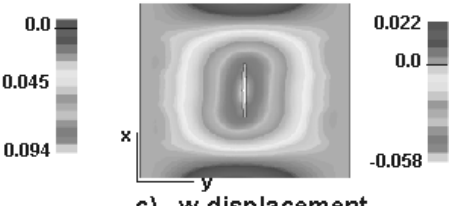

c) w-displacement

\section{Figure 19. Predicted displacements for specimen with horizontal slot.}

The linear buckling analysis of the damaged specimen predicted the first mode to be $14.73 \mathrm{kips} / \mathrm{in}$.

A photograph of the damaged specimens, TP-4 and TP-7 is shown in Figure 17. These specimens contain 34 strain gages that are located at the quarter length of the specimen and adjacent to the end of the slot.

The damaged specimens were loaded in compression at the rate of $5 \mathrm{kips} / \mathrm{min}$. until failure. The failure loads are shown in Table 2 for each specimen. The average failure load for the two specimens is 7.65 kips/in. The residual strength of the specimens with a horizontal slot is 37 percent of the residual strength of the undamaged specimens. A plot of the specimen axial end shortening and transverse in-plane displacement as a function of load is shown in Figure 20. The stiffness of each specimen is shown in column 3 of Table 2. The average specimen stiffness of 100.2 kips/in./in. and is approximately 12 percent below the computed stiffness of 114 kips/in./in. The transverse in-plane displacements are also shown in Figure 20 as dashed lines. Specimen TP-4 transverse in-plane displacement is the same as the analysis predictions

Table 2. Failure load and stiffness for specimens with a horizontal slot.

\begin{tabular}{ccc}
\hline \hline $\begin{array}{c}\text { Specimen } \\
\text { number }\end{array}$ & $\begin{array}{c}\text { Failure load, } \\
\text { kips/in. }\end{array}$ & $\begin{array}{c}\text { Stiffness } \\
\text { kips/in./in. }\end{array}$ \\
\hline TP-4 & 7.80 & 103.1 \\
TP-7 & 7.51 & 97.3 \\
\hline \hline
\end{tabular}

until a failure at approximately 5.5 kips/in. The analysis predicted the in-plane displacement to be 14 percent of axial displacement. Specimen TP-7 does not show any in-plane displacement until the previously noted failure.

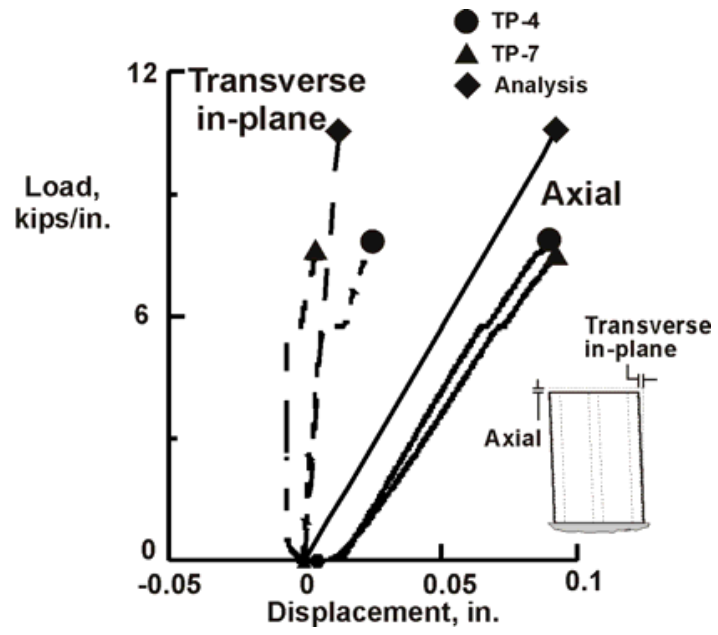

Figure 20. Axial and transverse in-plane displacements as a function of applied load.

Strain gage results from two strain gages adjacent to the slot are shown in Figure 21. Strain gage 15 is at the slot end and gage 16 is located 0.1 -inch from gage 15. As shown in Figure 21 both specimens had an initial failure at approximately $5.5 \mathrm{kips} / \mathrm{in}$. Although the strain in gage 15 on specimen TP-7 is twice the strain in gage 15 on specimen TP-4, the strains at gage 16 are nearly equal in both specimens.

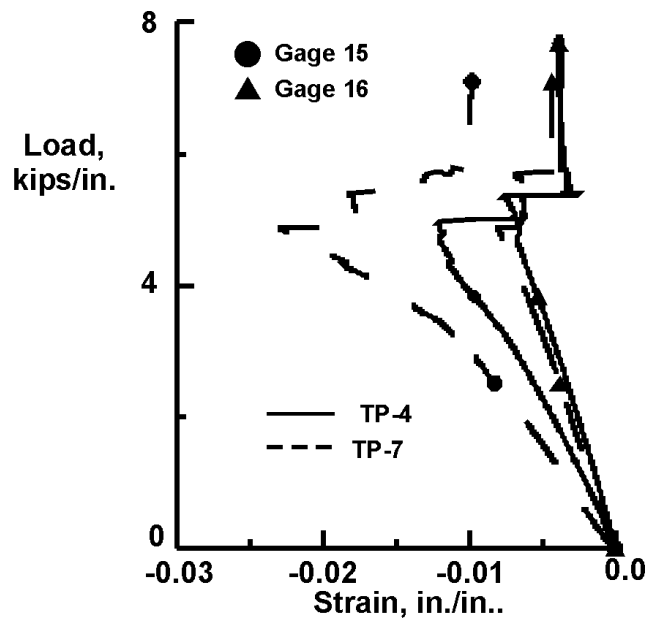

Figure 21. Results from gages at end of slot. 
The profiles of both specimens determined by the image correlation system are shown in Figures 22 and 23. An option available to the image correlation system is to add a second system of cameras, etc to be able to focus on a local area of the specimen. For these specimens a local, 4-inch by 4-inch, area was defined at one end of the slot. This local image area was painted white with black painted dots while the global image area was covered with a 0.004-inch-thick vinyl with the black pattern printed on it. This local area can be observed in Figures 22 and 23 as a square area at the slot end depressed from the surrounding area. Most of specimen TP-4 varies \pm 0.010 -inches from the theoretical plane. A local area near one edge varies up to 0.05 from the plane. The profile of specimen TP-7 (Figure 23) varies from -0.005 -inch to +0.060 inches from a theoretical plane.

The w-displacement field and $\varepsilon_{y y}$ strain field shown in Figure 24 is the first image after any failure is observed in TP-7, which was at a load of $5.73 \mathrm{kips} / \mathrm{in}$. The local failure starts at the left upper corner of the slot as shown in Figure 24a. The strain at the point of failure is $0.0063 \mathrm{in}$./in. as shown in Figure 24b and

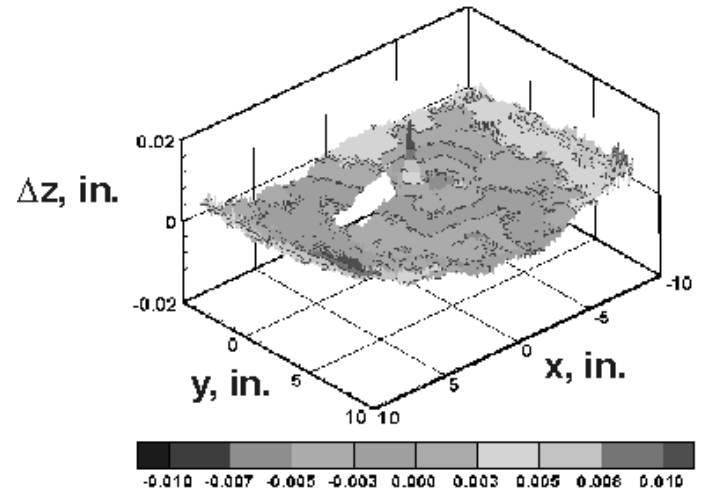

Figure 22. Profile of specimen TP-4.

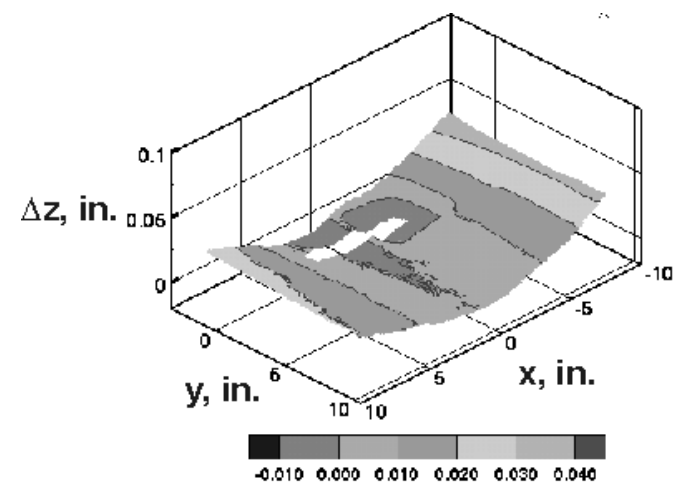

Figure 23. Profile of Specimen TP-7. compares well with adjacent gages shown in Figure 21. Two images later at a load of $5.82 \mathrm{kips} / \mathrm{in}$. failure starts at the right side of the slot as shown in Figure 25. The local failures progress up-and-to-the left and down-andto-the-right until total specimen failure at $7.51 \mathrm{kips} / \mathrm{in}$. Specimen TP-4 failed in a similar manner.

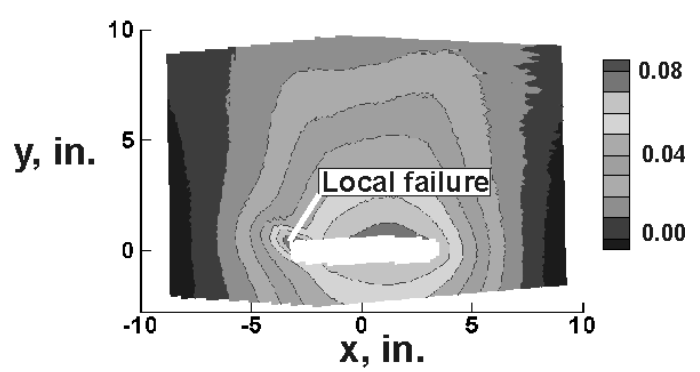

a) w, displacement, in.

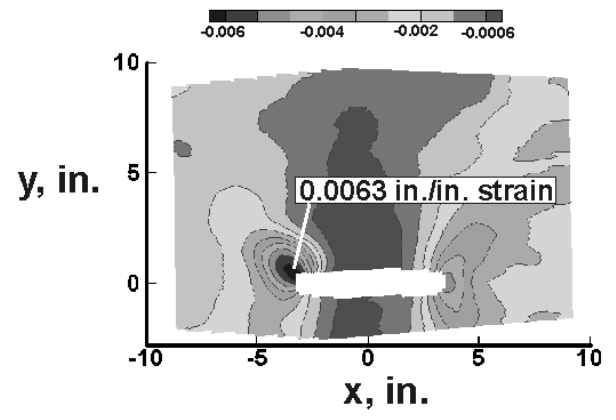

b) $\varepsilon_{y y}$ strain.

Figure 24. Specimen TP-7 displacement and strain fields at 5.73 kips/in. compression load.

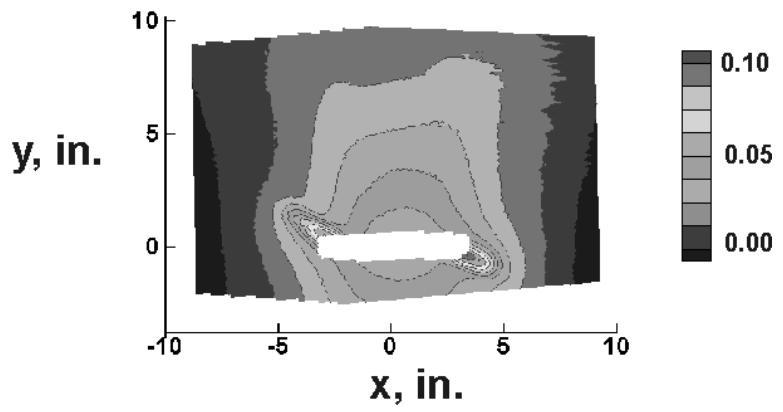

Figure 25. Out-of-plane displacement contours for specimen TP-7 at $5.82 \mathrm{kips} / \mathrm{in}$ compression load. 
Both specimens, TP-4 and TP-7, failed in a similar manner. A photograph of the stringer side of specimen TP-4 is shown in Figure 26. As indicated in the figure the failure progressed from the end of the cut up or down across the skin. Once the failure intersected the stiffener the failure path turned perpendicular to the stiffener and continued to the edge of the panel.

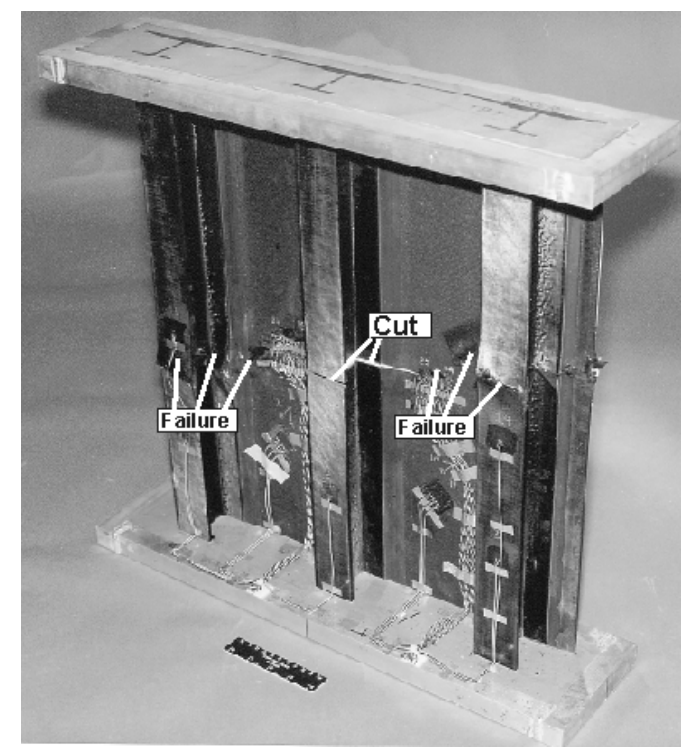

Figure 26. Photograph of failed in specimen TP4.

Inclined cut. Specimen TP-5 also had the center stiffener cut similar to specimens TP-4 and TP-7 except the cut was rotated $15^{\circ}$ from the horizontal as shown in Figure 27. The STAGS finite element model of the specimen with the inclined cut is shown in Figure 28. This model contains 12,702 quad elements and 12,429 nodes. Predicted displacement results are shown in Figure 29 for a specimen with an inclined slot. These contours do not show a predominantly skewed pattern, but the analysis does predict the transverse in-plane displacement to be 16.8 percent of the axial displacement. This predicted transverse in-plane displacement is approximately three percent higher than the prediction for specimens with a horizontal slot. The displacement contours in Figure 29b indicate the load redistribution around the central slot. The large triangular area to the right of the slot in Figure 29b indicates no axial displacements. The predicted out-ofplane displacements are shown in Figure 29c. These displacements are different than the displacement for a specimen with a horizontal slot. The top end of the slot as shown in Figure 29c deflects in the positive direction (into the paper) while the bottom end deflects in the

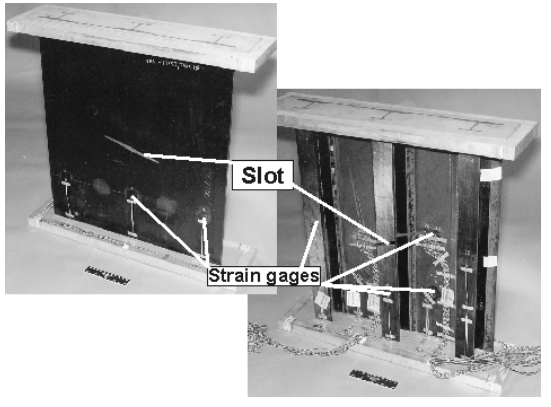

Figure 27. Specimen TP-5 with inclined slot.

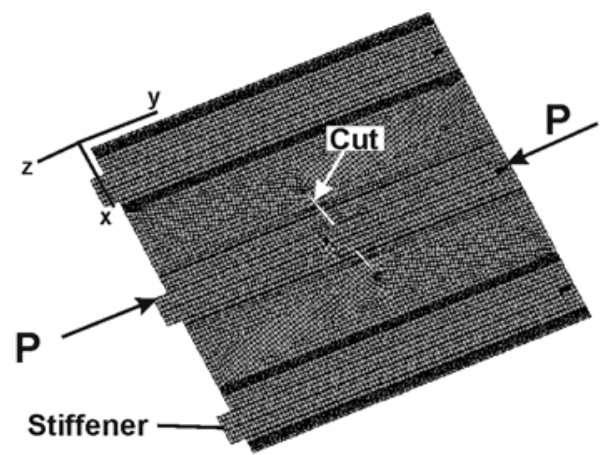

Figure 28. Finite element model of specimen with inclined slot.

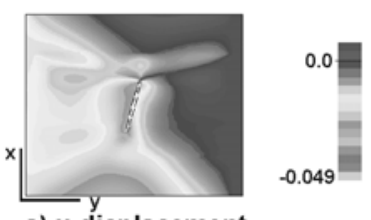

a) u-displacement

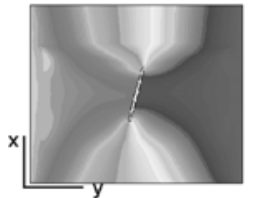

b) v-displacement

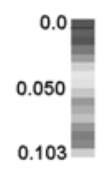

\section{Figure 29. Predicted displacements for specimen with a inclined slot.}

negative direction. This is entirely different than the bulge predicted for the specimen with a horizontal slot. 
The linear buckling analysis of the specimen with an inclined slot predicted the first buckling mode to be at a load of 14.1 kips/in.

Specimen TP-5, shown in Figure 27, was loaded in compression at the rate of $5 \mathrm{kips} / \mathrm{min}$. until failure occurred at $7.54 \mathrm{kips} / \mathrm{in}$. The residual strength of specimen TP-5 is 37 percent of the residual strength of the undamaged specimens. A plot of the axial shortening and in-plane displacement as a function of load is shown in Figure 30. The specimen stiffness of

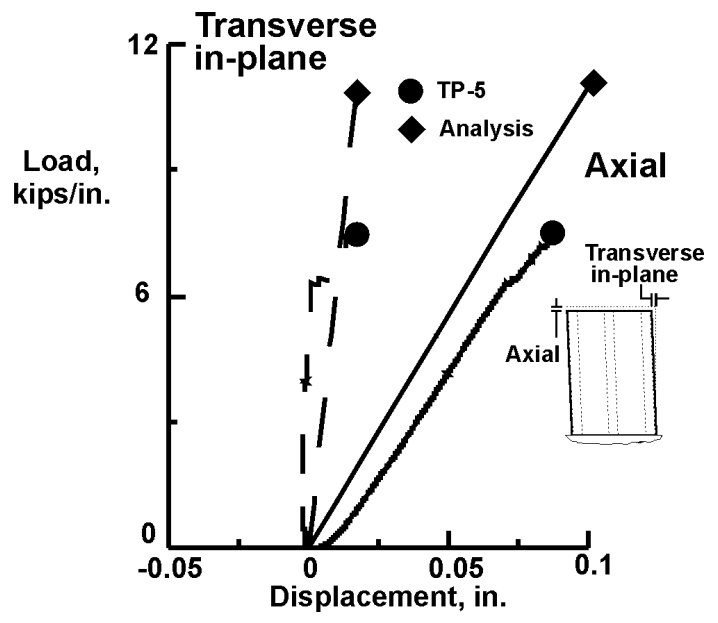

Figure 30. Axial and transverse in-plane displacement as a function of applied load for specimen TP-5.

$96.1 \mathrm{kips} / \mathrm{in} . / \mathrm{in}$. is approximately 13 percent below the computed stiffness of $110.1 \mathrm{kips} / \mathrm{in} . / \mathrm{in}$. The in-plane displacement for specimen TP-5 is linear until an apparent failure occurred at a load of $6.3 \mathrm{kips} / \mathrm{in}$.

The w-displacement field and $\varepsilon_{\mathrm{yy}}$ strain field for specimen TP-5 shown in Figure 31 is for a load of 6.32 kips/in. which are just prior to the failure initiation. Figure 31a indicates that the out-of-plane displacement is in the same direction on both sides of the centerline. This displacement field does not match the analysis result, which predicts the skin to deflect in opposite directions on each side of the centerline. The darker area at the right end of the slot in Figure 31b indicates the maximum strain in the image area and the strain is higher than on the left side of the slot. The displacement field shown in Figure 32 is at a load of $6.33 \mathrm{kips} / \mathrm{in}$. and indicates starting of delamination at the right side of the slot, where the highest strain was indicated in Figure 31b. The displacement field at a load of 7.45 kips/in., which is near failure, is shown in Figure 34. The failure can be seen emanating from

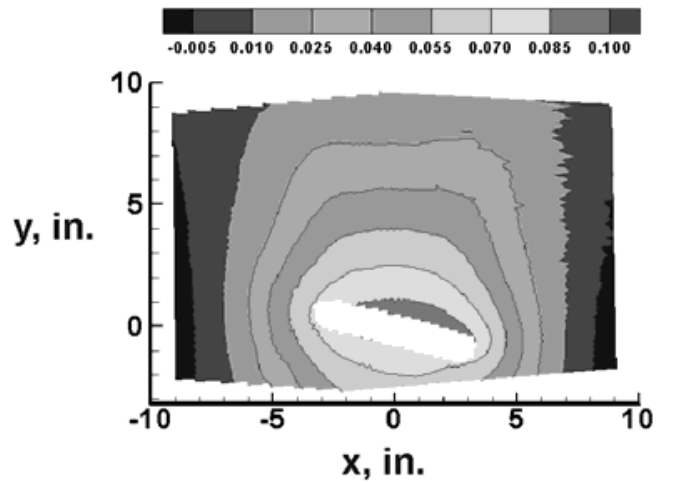

a) w displacement

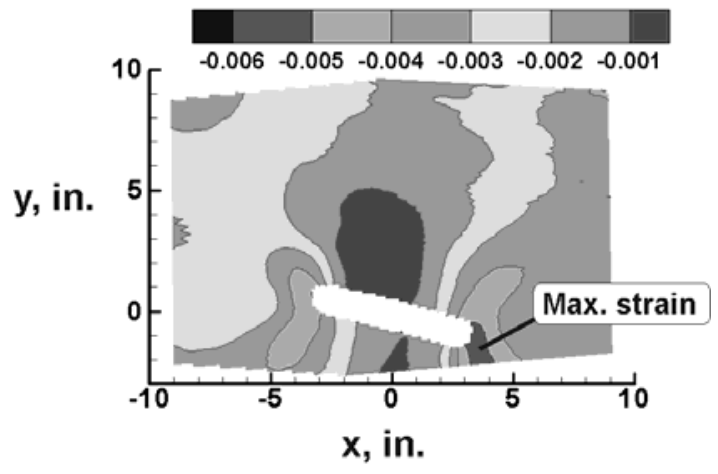

b) $\varepsilon_{y y}$ strain

Figure 31. Experimental displacement and strain fields for specimen TP-5 for $\mathrm{Ny}=6.32 \mathrm{kips} / \mathrm{in}$.

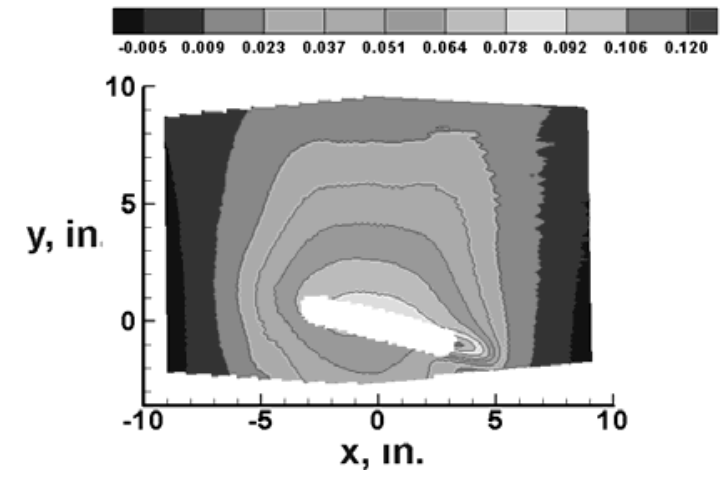

Figure 32. W-displacement field on specimen TP-5 at Ny $=6.33$ kips/in.

both ends of the slot and going upward on the left side and downward on the right side. 


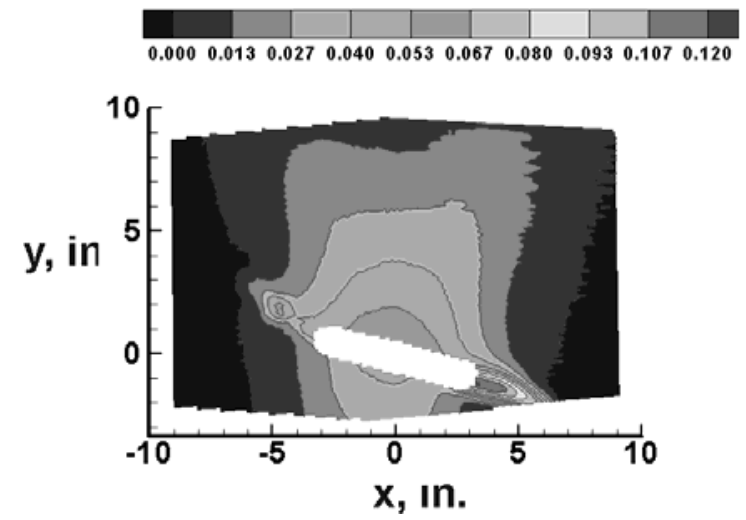

Figure 33. Experimental w-displacement field on specimen $\mathrm{TP}-5$ for $\mathrm{Ny}=7.45 \mathrm{kips} / \mathrm{in}$.

Failed specimen TP-5 is shown in Figure 34. The failure started at each end of the slot and progressed up or down until the stiffener location and then turned closer to a direction perpendicular to the stiffener and progressed to the specimen edge.

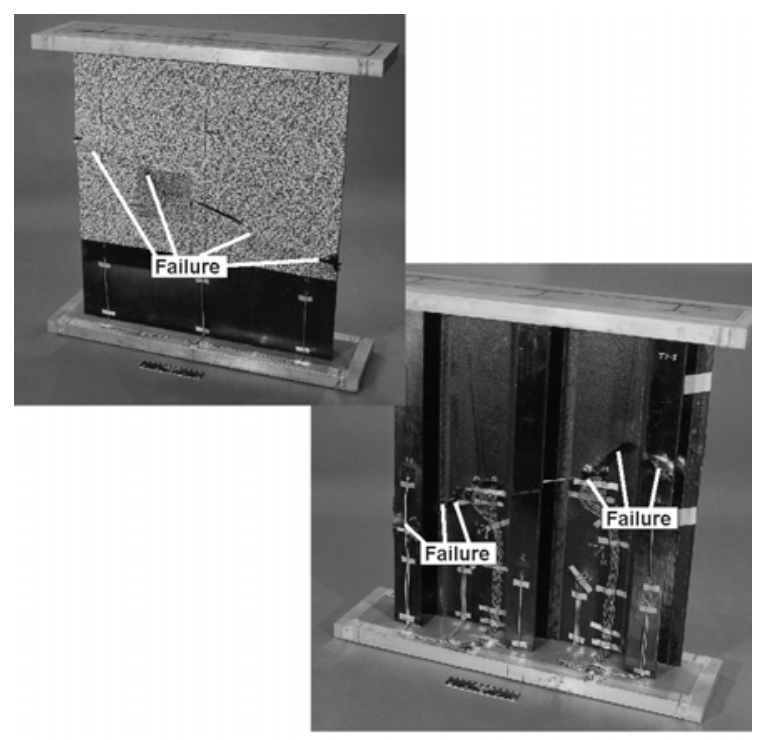

Figure 34. Failed specimen TP-5.

\section{Impact damage}

Specimens TP-3 and TP-8 were impacted at an energy level of 500 in.-lbs on the skin side opposite the ramp between the skin and the built-in skin reinforcement under the I-stiffeners shown in Figure 35. The impact was at the specimen mid-length approximately 2-inches from the specimen centerline. The impact produced barely visible impact damage with dent depth of 0.008-inches (TP-3) and 0.005inches (TP-8).

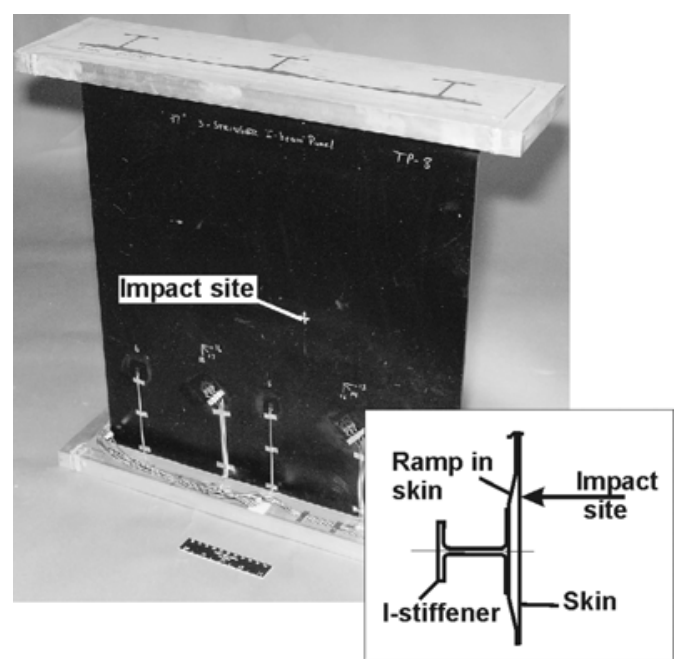

Figure 35. Specimen TP-8.

The profile of specimen TP-8 is shown in Figure 36 which covers approximately 60 percent of the specimen area. The specimen flatness varies from 0.015 -inches to +0.045 -inches from a theoretical plane. As indicated previously, the correlation system has an option to view a local area inside a global area. The local area around the impact site on specimen TP-8 is also shown in Figure 36 as a 3-D view. The depth of the surface dent is 0.005 -inches which is identical in magnitude to the value determined using a depth micrometer. The specimen curves from the center to the edges by up to 0.045 -inches.

The impacted specimens, TP-3 and TP-8, were loaded in compression at the rate of $20 \mathrm{kips} / \mathrm{min}$. until failure. The failure loads are shown in Table 3 for each specimen. The average failure load was $14.97 \mathrm{kips} / \mathrm{in}$. The average residual strength of the impacted specimens is 73 percent of the undamaged strength. A plot of the impacted specimen axial shortening as a function of applied load is shown in Figure 37.

Table 3. Failure load and stiffness for impacted specimens.

\begin{tabular}{ccc}
\hline \hline $\begin{array}{c}\text { Specimen } \\
\text { number }\end{array}$ & $\begin{array}{c}\text { Failure load, } \\
\text { kips/in. }\end{array}$ & $\begin{array}{c}\text { Stiffness, } \\
\text { kips/in./in. }\end{array}$ \\
\hline TP-3 & 14.07 & 136.21 \\
TP-8 & 15.87 & 136.3 \\
\hline \hline
\end{tabular}



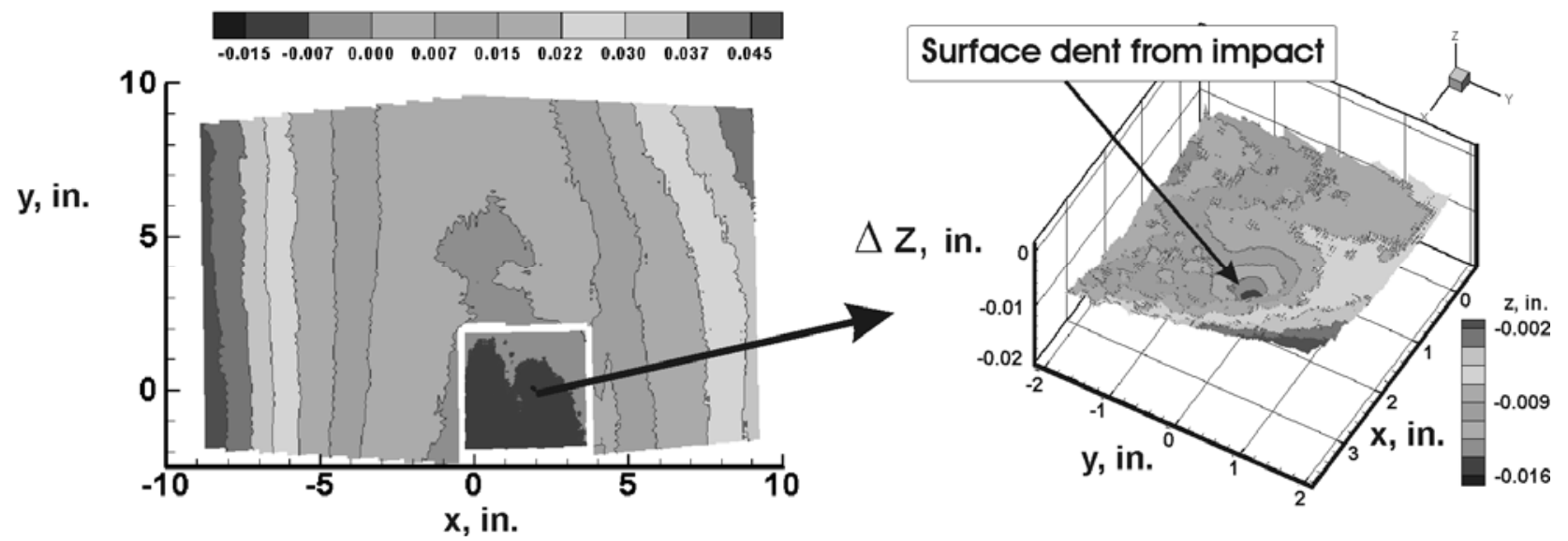

Figure 36. Profile of specimen TP-8.

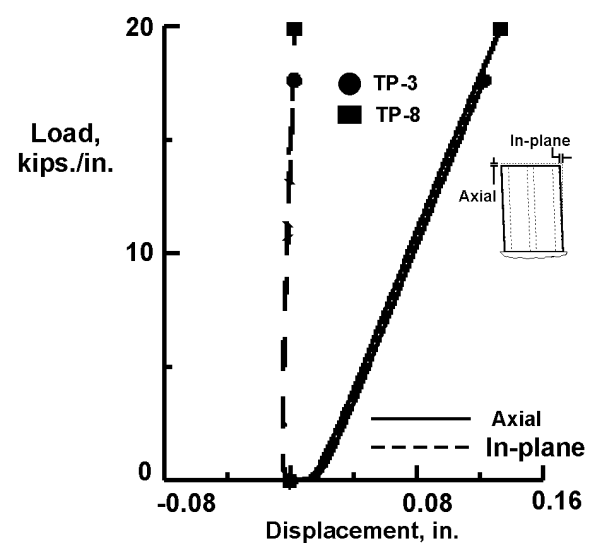

Figure 37. Axial and in-plane displacement as a function of load for impacted specimens.

The stiffness of each specimen is shown in column 3 of Table 3. The average stiffness of the impacted specimens is $136.26 \mathrm{kips} / \mathrm{in} . / \mathrm{in}$., which is 93 percent of the average stiffness of the undamaged specimens. LVDT results indicated very little displacement in the transverse in-plane direction. A series of contour plots from the image correlation system are shown in Figure 38 indicate delamination growth. The area shown in Figure 38a and identified by " $X$ " is adjacent to the impact area and appeared at a much lower load than indicated as an area setting above the adjacent area but did not indicate any significant growth. Comparison of Figures 38a and 38b indicate the area has a significant growth in size for approximately a $0.5 \mathrm{kip} / \mathrm{in}$. increase in load. An increase in load of $0.17 \mathrm{kip} / \mathrm{in}$. increases the size of the delamination areas and the magnitude of total deformation in the surrounding area as indicated by the increase in the contour level of the dark area as shown in Figure 38c. The last image taken before failure is shown in Figure 38d which again indicates a significant growth in thedelamination size for 0.2 kip/in. increase in load. The skin out-of-plane displacements (tear drop shaped areas) show very little change when the delamination increases in size.

The in-plane contours for specimen TP-8 at $\mathrm{N}_{\mathrm{y}}$ $=15.63 \mathrm{kips} / \mathrm{in}$. are shown in Figure 39. The in-plane contours shown in Figure 39 indicate some in-plane displacement contrary to the minimum displacement indicated by the LVDT's.

The failed impacted specimen TP-8 is shown in Figure 40. On the skin damaged due to impact the failure progressed straight across the skin and stiffener to the edge of the panel on one side. Along the other side failure progressed at approximately a $45^{\circ}$ angle to the stiffener, crossed the stiffener and moved to the specimen edge at approximately a right angle to the stiffener.

\section{Concluding Remarks}

A method has been developed for compression testing of tailored composite specimens with in-plane shear coupling that allows the specimen to deform from a rectangle to a parallelogram. The response of eight tailored composite panels have been studied using this test method.

Three specimen configurations have been evaluated: 1) Undamaged (as-fabricated), 2) Center stringer and adjacent skin severed, and 3) Barely visible impact damage on the skin at a critical location. 


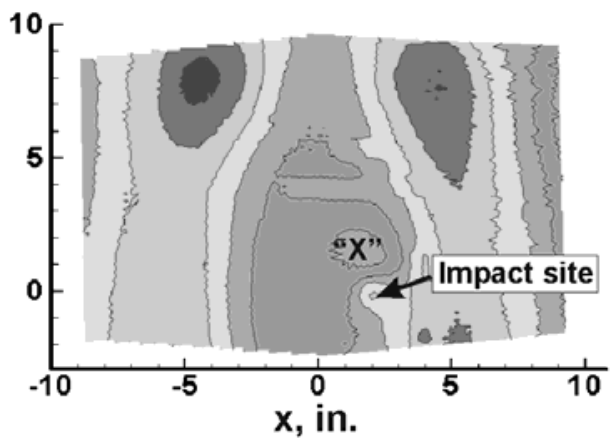

a) $\mathrm{N}_{\mathrm{y}}=14.95 \mathrm{kips} / \mathrm{in}$.

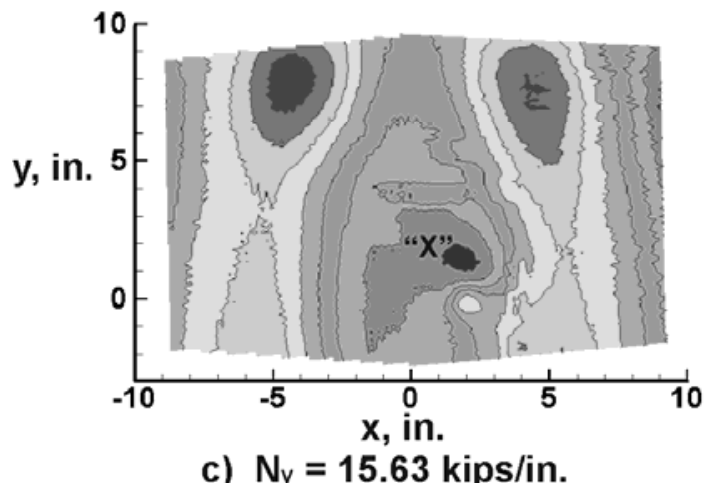

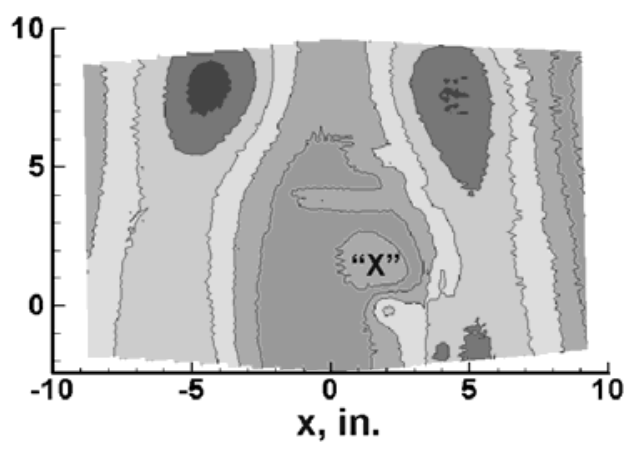

b) $\mathrm{N}_{\mathrm{y}}=15.46 \mathrm{kips} / \mathrm{in}$.

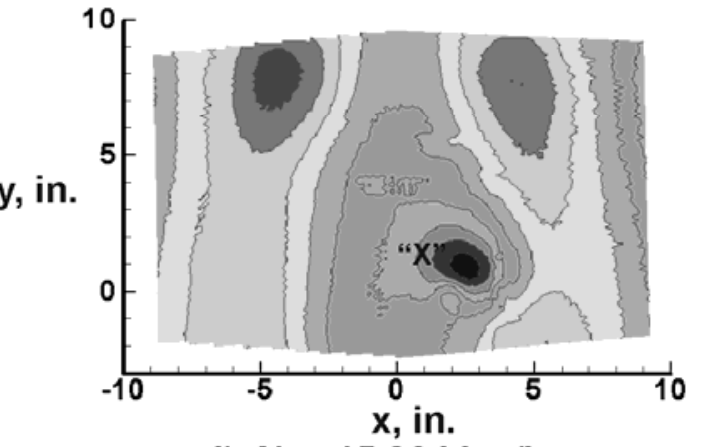

d) $\mathrm{N}_{\mathrm{y}}=\mathbf{1 5 . 8 3} \mathrm{kips} / \mathrm{in}$.

Figure 38. Progression of increasing out-of-plane displacements in the vicinity of the impact damage site.

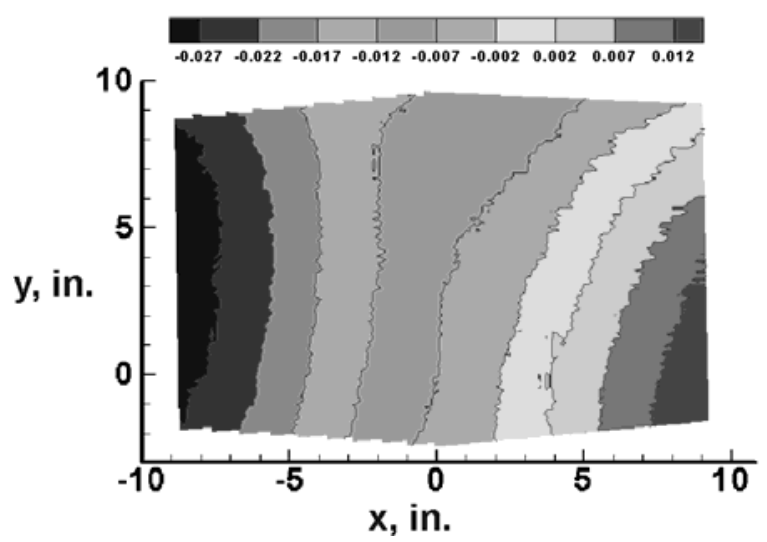

Figure 39. In-plane contours for specimen TP-8 for $N_{y}=15.63$ kips/in.

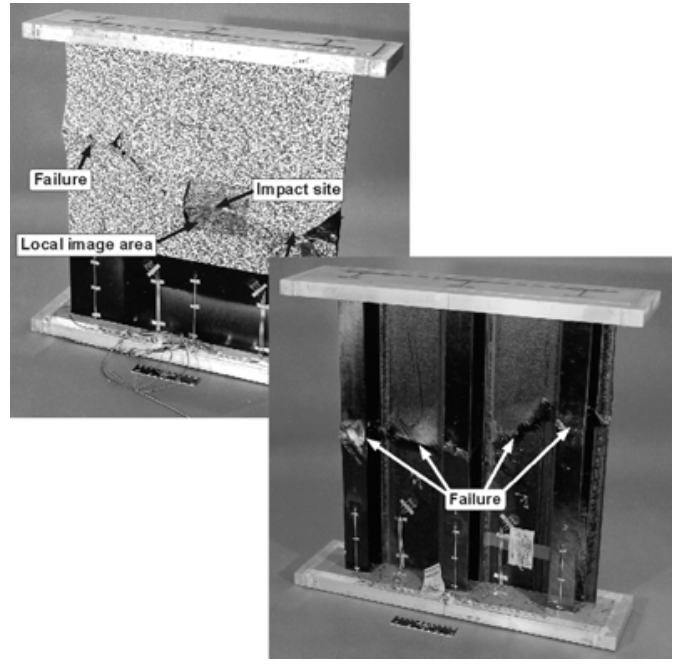

Figure 40. Failed specimen $\mathrm{TP}-8, \mathrm{Ny}=\mathbf{1 5 . 8 7}$ kips./in. 
The three undamaged tailored composite specimens that have been tested and the average strength was 90 percent of a specimen tested previously that had the same geometry with a balanced $\pm 45^{\circ}$ skin. The surface profiles of the panels indicated most of the panel was within \pm 0.010 -inches with some variations at the edge to as much as 0.06 -inches. The average specimen axial stiffness is within 5 percent of the computed stiffness from the STAGS analysis. The inplane coupling is shown to induce transverse in-plane displacement magnitudes that are 17 to 25 percent of the axial displacements.

The specimens with the center stiffener and adjacent skin severed had a residual strength of 37 percent of the undamaged specimens. Accounting for the net section loss due to introducing the cut, this amounts to a strength reduction of approximately 40 percent. The initiation of a local failure on the surface, viewed with the image correlation system was determined for the slotted specimens. The failures progressed upward or downward from the end of the slots depending on the local anisotropy of the material.

Specimens impacted for barely visible impact damage exhibited an average residual strength that was 73 percent of the undamaged specimen strength. The delamination growth with increasing load was tracker using the image correlation system. The impact damage pattern is also skewed due to anisotropy and results in an unsymmetric growth to failure.

\section{$\underline{\text { References }}$}

1. Popelka, D., Sheffler, M., and Bilger, J.

"Correlation of Test and Analysis for the $1 / 5^{\text {th }}$

Scale V-22 Aeroelastic Model.” Journal of the American Helicopter Society, Vol 32, (2), April 1997.

2. Popelka, D., Lindsay, D., Parham, T.,Jr., Berry, V., and Baker, D., "Results of an Aeroelastic Tailoring Study for a Composite Tiltrotor Wing," Presented at the $51^{\text {st }}$ Annual American Helicopter Society Form, Fort Worth, TX, May 1995.

3. Corso, L. M., Popelka, D. A., Nixon, M. W., "Design, Analysis, and Test of a Composite Tailored Tiltrotor Wing." Presented at the $53^{\text {rd }}$ annual American Helicopter Society Forum, Virginia Beach, VA, April 1997.

4. Rousseau, C. Q., Baker, D. J., Hethcock, J. D., "Paramertic Study of Three-Stringer Compression-After-Impact Strength," Composite Structures: Theory and Practice, ASTM STP 1383, Oct. 2000, pp 72-104.

5. Helm, J. D., McNeil, S. R., Sutton, M. A., "Improved Three-Dimensional Image Correlation For Surface Displacement Measurements," Optical Engineering, Vol. 35, No 7, July 1996, pp. 1911-1920.

6. Brogan, F. A., Rankin, C. C., and Cabiness, H. D., "STAGS Users Manual," Lockheed Palto Alto Research Laboratory, Report LNSC P032594, 1994. 